\title{
Rostos goianos na migração
}

\author{
Juliana dos Santos Pereira Moraes*
}

\section{Introdução}

Este artigo é parte da vivência do trabalho de campo, realizado em Lisboa entre os anos de 2007 a 2009, que culminou na dissertação de mestrado "As Meninas do Pequi fora do Sertão: goianas imigrantes em Lisboa" (PEREIRA, 2009) ${ }^{1}$ que contou com a orientação do Professor Doutor José Manuel Sobral ${ }^{2}$. A escolha por estudar as goianas não se deu por um acaso. Pelo fato de ser de Goiânia e precisar trabalhar durante a realização do mestrado, consegui conhecer muitas outras goianas pois, embora tivesse um estatuto de estudante, compartilhávamos da mesma condição de imigrante, trabalhadora e ainda da mesma memória regional.

Nesse contexto conheci mais de cinquenta goianas, com as quais realizei vinte e oito entrevistas estruturadas e cinco "histórias de família"3, o que permitiu um estudo mais aprofundado. Para conseguir realizar a pesquisa não tive dificuldades pois, à medida que eu conhecia alguma goiana, sempre tinha indicação de mais outras pessoas. Também fiz visitas ao Consulado Brasileiro em Lisboa, Casa do Brasil, à restaurantes de comida brasileira, como Chimarrão, Sabor a Brasil, Sabores da Picanha; à casas de dança, como Armazém F, Cenoura; e a estabelecimentos comerciais de um modo geral. Em todos esses lugares é facilmente possível conhecer brasileiros e muitas mulheres goianas.

Minhas interlocutoras geralmente tinham entre vinte e trinta anos. Eram oriundas de Goiânia ou de cidades vizinhas, como Aparecida de Goiânia e Anápolis. Saíram do Brasil, solteiras. Trabalhavam no comércio ou no mercado informal - como manicures, cabeleireiras, massagistas e recebiam em torno de dois salários mínimos. Viviam na casa dos pais; tinham como objetivo inicial conhecer outro país, trabalhar, melhorar de vida, ajudar seus parentes e, se possível, casar.

Quando me perguntavam de que lugar do Brasil eu vinha, ao responder que era de Goiás, sempre me diziam que havia muitas goianas vivendo em Lisboa. Por muitas vezes isso me inquietou. $\mathrm{O}$ que elas fazem? Como avaliam seu projeto

* Doutoranda em Antropologia pelo ISCTE (Instituto Universitário de Lisboa) e Mestre em Antropologia Social e Cultural pelo Instituto de Ciências Sociais da Universidade de Lisboa. 
migratório? Como lidam com os estereótipos associados à mulher brasileira? Qual é sua trajetória de vida? Do que sentem saudade e quais foram as redes que elas estabeleceram para o projeto migratório, foram alguns questionamentos que eu tinha à priori.

\section{Migrar para onde?}

As emigrantes goianas, ao falarem do seu projeto migratório inicial, confirmam o que MARGOLIS (2003) ressalta quando diz que o destino preferencial dos brasileiros eram os Estados Unidos da América (EUA). Atualmente, devido à inacessibilidade desse destino, o sonho dessas mulheres passa a ser a Europa, e Portugal passa a ser a porta de entrada por estar mais acessível economicamente e até mesmo geograficamente, pois não precisam se arriscar em fronteiras, como ocorre na fronteira entre o México e os EUA.

Numa pesquisa realizada em 2008, pela Assessoria para Assuntos Internacionais de Goiás, Elie Chidiac (2011), chefe dessa assessoria, explica que a partir de 2005, o México passou a exigir passaporte dos brasileiros que viajavam ao o país para tentarem entrar nos EUA. Ocorreu uma inversão na rota de imigração dos goianos. Oitenta por cento (80\%) dos imigrantes que saíam de Goiás pretendiam ir para os EUA. Mas, devido à crise econômica enfrentada pelos norte-americanos, aliada à queda do preço do dólar, os brasileiros passaram a procurar o sonho de uma vida melhor na Europa, principalmente em países como Portugal, Espanha e Reino Unidos.

Para as goianas, embora tenham preferência pelos Estados Unidos, as dificuldades para se obter o visto e para se cruzar a fronteira do México fazem com que elas prefiram ir para Portugal. Atualmente, os brasileiros continuam a utilizar apenas o passaporte para entrar em solo europeu, podem permanecer sem visto durante 90 dias, mas é claro que se submetem à autoridades alfandegárias, que podem também negar a entrada. Em uma das entrevistas Janaína descreve como foi a escolha do destino.

Primeiramente eu tentei o visto para os Estados Unidos. Fui a uma agência de viagens, que fornecia informações de como proceder na entrevista, para conseguir o visto. Paguei uma grana para esta agência, que levou eu e minha mãe, para Brasília. Disseram-me que se eu fosse com minha mãe era mais fácil de conseguir o visto, pois eu só tinha 17 anos. Compramos roupa nova, fomos ao salão, arrumamos o cabelo. Tínhamos que parecer ricas. Então dissemos lá, que estávamos indo a passeio para a Disney. Não sei porque mas só concederam o visto pra minha mãe. Ela era funcionária do Estado já aposentada. 
Não entendi. O que eles pensaram? Ela conseguiu o visto de 10 anos e nem iria viajar. Eu é quem precisava do visto. Gastei todo meu dinheiro, depois disso tentei novamente e foi novamente negado. Eles viram na minha cara que eu não tinha condições financeiras para realizar aquela viagem e entrar nos Estados Unidos e de outra forma, eu achei que era muito arriscado (Janaina4, 26 anos, trabalha com o cuidado de idosos em diversas casas, há 8 anos em Portugal).

Para as goianas, Portugal se tornou a opção possível devido a uma série de fatores, como os acordos bilaterais entre Portugal e Brasil, que facilitam a entrada sem necessidade de visto e a possibilidade de permanência dos imigrantes brasileiros; a facilidade de acesso a outros países europeus; as afinidades linguísticas; o fato de muitas delas conhecerem alguém em Portugal e isso lhes permitir um estabelecimento de redes, a priori, tornando o projeto migratório muito mais seguro.

Eu não pretendo voltar, aqui posso comprar o que meu filho quiser. Acha que eu conseguiria dar estas coisas para ele se eu morasse no Brasil? (Marina, 33 anos, gerente de um restaurante em Lisboa, há 8 anos em Portugal).

Eu sai de Goiânia para Portugal para trabalhar, para ter uma vida melhor. Lá eu não conseguia trabalho para me manter. Mas, eu acabei criando raízes aqui em Portugal. Tenho meu filho e meu marido portugueses (Adriana, 30 anos, dona de casa, há 10 anos em Portugal).

Agora que eu tenho cidadania europeia, sou portuguesa, pretendo ir para outro país, porque aqui está muito difícil. Quero ir para outro pais que forneça melhores condições de vida. Eu primeiramente pensava em ir para Londres. Mas, depois de ter vivido lá por 2 meses, acho que seria melhor ir para outro país (Lara 29 anos, morou 11 anos em Portugal).

À medida que elas chegam e vivenciam esse projeto migratório, muitas coisas acontecem e se o objetivo era viver em Portugal por um tempo até conseguirem organizar suas vidas e depois retornarem, com o passar do tempo, suas vidas vão se alterando, de modo que a maioria das interlocutoras, como Marina e Adriana, não pretende retornar mais ao Brasil. Uma motivação é o estabelecimento de vínculos, seja devido ao casamento com Portugueses ou pelos filhos terem nascido em Portugal. 
Elas querem garantir que os filhos, no futuro, possam escolher o país que queiram viver, pois os filhos de brasileiros nascidos em Portugal, embora sejam brasileiros, após os cinco anos, passam a ter direito à nacionalidade europeia, obtendo, assim, uma dupla-nacionalidade. Além de Portugal não ser a primeira opção, para muita dessas mulheres, como diz o relato de Lara, também não será o destino final, com a obtenção da cidadania portuguesa, elas podem não só circular pela Europa como também escolher outro país para viver.

\section{Imagens e Fronteiras}

Em Portugal embora exista um discurso dos portugueses de que os mesmos direitos deles sejam também dados aos imigrantes, é no cotidiano que operam conflitos identitários entre nacionais e as goianas, que passam a ser nacionais (adquirem a cidadania portuguesa). A vida nas nossas sociedades depende daquilo a que Alfredo SCHUTZ (1962, apud GIDDENS, 2008:86) chamou "tipificações", isto é, a classificação que damos, segundo a nossa experiência anterior, aos fenômenos com que confrontamos.

Quando encontramos alguém, imediatamente construímos uma ideia de quem a pessoa é. As tipificações permitem-nos classificar o mundo e servem para nos orientar. Todavia, elas podem tornar-se uma estereotipificação, entendendo esse termo como uma generalização abusiva acerca de uma pessoa, pelo fato de ela pertencer a um determinado grupo. $O$ racismo, o sexismo e as atitudes preconceituosas às pessoas portadoras de deficiência são exemplos disso. Também o são as atitudes ante os estrangeiros e, em particular, em face aos emigrantes. $O$ estereótipo preconcebido que as pessoas de uma sociedade criam acerca dos imigrantes tem implicações no modo como eles se veem e vivem nesse determinado contexto.

De muitas formas, esses estereótipos também determinam a maneira de interação entre nacionais e não nacionais. Esta interação faz com que as pessoas recriem uma definição de quem elas são, gerando mecanismos de autoidentificação. Essa auto atribuição de identificações é, segundo BARTH (1998:9), o resultado da capacidade que estas pessoas têm de manter simbolicamente as suas fronteiras de diferenciação que o distinguem dos outros.

Os portugueses olham pra gente e só no olhar você sabe né, olham pra gente e pensam que somos uma dessas, você sabe! Aqui tem muitas, (Rafaela, 22 anos).

PADILHA (2006) acredita que os portugueses associam as mulheres brasileiras a uma imagem estereotipada de prostituição, em razão da sensualidade tropical que lhes é imputada da miscigenação, das imagens de índias dos séculos XV e $\mathrm{XVI}$ que viviam praticamente nuas, do Carnaval e atualmente das telenovelas e da imprensa. 
Ele me perguntou se eu era brasileira, aí, balancei a cabeça, disse para ele que eu tinha acabado de chegar. Então, ele me perguntou se eu estava a passear, aí eu disse que vim a trabalho. Aí ele respondeu, mas a menina vai fazer o que? No tom da pergunta eu senti que tinha algo por trás, mas não querendo ser mal educada respondi que ainda não sabia (Fernanda, 26 anos, dona de casa, há 6 anos em Portugal).

Segundo MACHADO (2006:246), os brasileiros e portugueses vivenciam uma experiência cotidiana mediada pelas construções estereotipadas e, nesse sentido, os imaginários são "aprisionados", aos quais os brasileiros podem se render, outras vezes, estimulá-los e outras, ainda, recusá-los. As mulheres goianas entrevistadas também se veem como alvo desses estereótipos e, por mais que elas queiram afastar isso, essa imagem está presente em seu cotidiano. Para corroborar essa ideia, Gabriela , numa forma de cumplicidade, diz.

Em algumas situações, a mulher brasileira em Portugal, acontece realmente dela ganhar um olhar "Ah! É brasileira", já com aquelas ironias que a gente sabe o que significa. Várias mulheres brasileiras vêm para Portugal, não só para Portugal, como para a Europa pra prostituir. Então, esse "Ah! é brasileira" né, a gente já fica com aquela coisa. (Gabriela, 25 anos, cozinheira, há 6 meses em Portugal).

As prostitutas aqui são tudo de Goiânia. Fiquei com muito medo de não me deixarem entrar. Quando você fala que é de Goiânia, lá na imigração, eles já ficam espertos e te deportam; eles falam que tão deportando a gente por causa de ar de simplicidade, tá te deportando é porque acham que somos prostitutas. Todos os dias você vai na internet e quando vê notícias de prostituição, pode saber que tem goiana no meio (Karine, 22 anos se referindo a reportagem: "Goianos são os mais deportados).

Ser brasileira em Portugal significa, para essas mulheres, carregar o peso do estereótipo de prostituta ou mesmo "mulher fácil". Ser goiana, em determinados contextos, reforça o estereótipo ainda mais, devido às redes de aliciamento veiculadas pelos noticiários. De acordo com a Folha Online ${ }^{5}$, há crescimento da prostituição de goianas na Europa, "há entre 3.000 e 5.000 goianas se prostituindo".

As portuguesas têm um lado muito mau, elas veem as brasileiras como prostitutas, e eu morei num quarto onde 
todas as brasileiras eram de Goiânia. E tem muita garota de programa de Goiânia. A i as portuguesas veem muita prostituição, e a maioria das prostitutas são de Goiânia. Mas, desculpe lá, também a mulher goiana é bonita, as mulheres são bonitas. Então, se você for em Marquês de Pombal, no Elefante Branco e se você começar a perguntar de onde você veio, você vai ver que a maioria é de Goiânia. Tem menina goiana pra dar com o pau (Grasiele, 27 anos, dona de casa, há 7 anos em Portugal).

Segundo ALMEIDA e REIS (2007:13), algumas portuguesas consideram a presença das brasileiras uma ameaça para a vida conjugal lusitana. Mas, para as goianas, essa ideia é reforçada por causa das redes de aliciamento de mulheres goianas e também pelo fato de existir um imaginário de considerá-las mais bonitas, criando outro estereótipo, o que liga a prostituição a "mulheres bonitas".

É claro que eles preferem casar com a gente. Além de sermos bonitas, nós tratamos eles muito melhor. Elas (se referindo as mulheres portuguesas) não dão carinho, não se cuidam, não se preocupam com a casa. Eu amo muito meu marido. Ele é muito bom para mim, ajuda minha família, faz tudo o que eu quero eu não namoraria com brasileiro. Eles só querem farra, são mulherengos (Grasiele, 27 anos, dona de casa, há 7 anos em Portugal).

Todavia, esses estereótipos nem sempre são negativos, pois é em consequência também deles que as mulheres brasileiras são consideradas pelos portugueses mais sedutoras, mais carinhosas e também melhores companheiras. Em razão deles as perceberem dessa forma, 72\% das imigrantes goianas disseram nas entrevistas que preferiam se relacionar com portugueses, por acharem que eles podem lhes proporcionar uma maior segurança, tanto financeira quanto afetiva. E apontaram, também, que eles são mais fiéis e tranquilos que os brasileiros. Queixaram-se ainda do fato de os brasileiros estarem sempre ligados à bagunça, festas com música alta, além de não possuírem estabilidade financeira para ter uma vida conjugal em Portugal.

Deste modo, as goianas, ao se relacionarem com seus parceiros, dinheiro, sensualidade, companheirismo e amor entrelaçam em um terreno ambíguo. Apesar destes relacionamentos muitas vezes se mostrarem marcados pelo interesse econômico, seja uma estabilidade financeira ou mesmo um modo de se legalizarem, eles estão permeados pelas noções dos estereótipos.

É relevante chamar a atenção que há não só a criação de estereótipos das imigrantes goianas (que podem ser estendidos às brasileiras em Portugal), mas também aos que elas criam com relação aos homens e mulheres portugueses, 
pois conforme relata Grasiele, "a mulher portuguesa não dá carinho, não se cuida e não cuida da casa". Há também o estereótipo criado para o homem brasileiro, pois de acordo com esse mesmo relato, este "só quer farra", o que parece fazer do europeu uma escolha mais acertada por elas e assim a relação entre brasileiras e portuguesas são permeadas por todos esses estereótipos.

\section{A goianidade como uma Fronteira Identitária}

No Brasil, as fronteiras em relação à identidade nacional raramente intervêm nas interações cotidianas. Pois, devido às dimensões deste país, a questão regional se faz presente no cotidiano dos seus habitantes. Segundo OLIVEN (1992:43), as identidades regionais no Brasil podem ser encaradas como reação a uma homogeneização cultural e como uma forma de salientar as diferenças culturais. Esta redescoberta das diferenças e a atualidade da questão da federação numa época em que o país se encontra bastante integrado do ponto de vista político, econômico e cultural sugere que no Brasil, o nacional passa primeiro pelo regional.

Entretanto, em um contexto migratório, as identidades regionais tendem a perder seu peso, pois todos os brasileiros são imersos numa identidade nacional. E ser brasileira em Portugal recebe os contornos estereotipados, associados às brasileiras no geral. Por exemplo, a goiana carrega consigo toda carga simbólica que apela para a "goianidade", sendo associada, em razão dos estereótipos regionais, à ruralidade. O contexto migratório pode, muitas vezes, esconder uma diversidade significativa de identidades brasileiras, que são cortadas complexamente por questões de classe entre a população imigrante, de temporalidade da imigração, de gênero, de ascendência portuguesa (por sua vez diferenciada por graus de ascendência), de cor/raça, de ocupação no mercado de trabalho, de religião, de origem regional, entre outras possíveis (MACHADO, 2006:12).

No caso das imigrantes goianas, as construções de ordem regional, são formuladas a partir de diferenças reais ou inventadas que operam como sinais diacríticos, isto é, sinais que conferem uma marca de distinção e operam como categorias que classificam pessoas e coisas, estabelecem limites e delimitam fronteiras identitárias, (OLIVEN,1992:26). Estes sinais associam a imagem do brasileiro à feijoada e à capoeira, ao futebol, ao samba, ao carnaval e fio dental ${ }^{6}$ e, segundo Ribeiro (1998:5), em São Francisco - EUA, muitos goianos assumem essa identidade e também os papéis de foliões, cabrochas e carnavalescos, pois se identificam com essas imagens.

Porém, na organização da experiência migratória e internamente ao cotidiano da "comunidade" brasileira em São Francisco, a identidade regional goiana se mantém, pois vivem nos mesmos edifícios, compartilham apartamentos 
e mantêm suas redes sociais baseadas em relações já existentes em Goiás. Tanto os goianos em São Francisco quanto as goianas em Lisboa compartilham dessa mesma experiência, de interajuda e também da ideia de uma "goianidade". Essa identidade foi construída, segundo COUTINHO (2005:1), devido à valorização ou revalorização da dimensão simbólica e da gestão do patrimônio cultural, a partir de um discurso político que ressaltava os aspectos regionais como o sertão, o rural, a comida, a hospitalidade e a música regional.

As goianas, como estão neste cotidiano lisboeta, ao se relacionarem com portugueses, brasileiros ou outros nacionais, têm sua identidade realçada. 0 conteúdo das identidades assumido pelas goianas implica suas delimitações de fronteiras, pois, para elas, ser goiana implica ser do Centro-Oeste e apelar para uma "goianidade, onde gado, cerrado, pequi, rio Araguaia e música country, supostamente, definiriam uma particularidade identitária" (RIBEIRO, 1999:72).

Em Lisboa, sempre ao encontrar outra goiana, uma das primeiras coisas que elas me falavam era da saudade de comer pequi. Segundo Sobral (2008), a memória é uma dimensão essencial da vida humana e a memória alimentar na sociedade receptora resgata a memória do lugar de origem. Por isso é tão importante essa relação do imigrante com sua memória gustativa.

Quando faço pequi, meus vizinhos ficam curiosos para saber o que é por causa do cheiro. Ele tem um cheiro muito forte. Inclusive, tenho em casa um monte de bolinhas congeladas (Graziele, 25 anos, desempregada, há 3 meses em portugal).

Quando falo de Goiânia, só me vem saudade. Tenho muita saudade. Tenho muita saudade de comer arroz com pequi. Eu adoro, pequi. Eu me lembro de quando saía na rua em Goiânia, principalmente na época do pequi, o cheiro exalava (risos). Nossa! Agora deu saudades de lá e dos amigos (Gisele, 28 anos, atendente de balcão, há 3 anos em Portugal).

Em Lisboa, há muitos supermercados voltados para os imigrantes brasileiros, como em Arroios, na Almirante Reis, nas estações de Comboio da Damaia e da Reboleira, mas ainda não é possível encontrar neles o pequi. As meninas só conseguem comê-lo em Lisboa, quando elas ou algum conhecido o trazem de Goiás. As goianas, ao falarem que sentem saudades de comer pequi, do arroz com pequi, do cheiro do pequi, do modo de comer o pequi, ou seja, através das suas nostalgias e memórias, elas encontram um meio de preservar sua "pertença" regional no contexto migratório. 


\section{Conclusões}

Estas considerações sobre a importância das fronteiras, ou linhas de demarcação na manutenção das identidades étnicas, aplicam-se, em nosso entender, às identidades regionais e às identidades nacionais em geral. As implicações da manutenção das fronteiras de que nos fala BARTH (1998) fazem com que os membros de um grupo étnico, ao interagirem com outros grupos, estabeleçam uma forma de comunicação.

Porém, a interação não leva a uma unificação. Há variações culturais. Mesmo havendo comunicação entre eles, há também uma grande resistência à assimilação cultural, pois o contato, em vez de provocar a aculturação, pode provocar o reforço das identidades. Desse modo, ao ouvirem música da sua região, ao recordarem o sabor da sua comida, as goianas mantêm uma fronteira que as separa das outras brasileiras, procurando proteger-se dos efeitos negativos do estereótipo. Ao mesmo tempo, as fronteiras políticas, administrativas e de cultura nacional que separam Portugal do Brasil fazem delas membro deste "outro" nacional, que é o conjunto das brasileiras.

Assim, a construção da identidade, fronteira/imigrante, mantém-se. Pois, se mantém também a fronteira (ter nacionalidade ou cidadania diferente) que separa, segundo SOBRAL (2008), o nacional do estrangeiro, mesmo quando o estrangeiro fala a mesma língua ou possui a mesma nacionalidade. Mesmo que, em Portugal, existam várias representações das brasileiras e do Brasil, e que os estereótipos, tanto de ser brasileira quanto de ser goiana, possam influenciar nas possibilidades de inserção na sociedade portuguesa, as goianas não deixam suas nostalgias e, através das suas memórias, carregam consigo sua identidade regional.

Segundo SANTOS (2005: 135), as identidades não são fixas nem imutáveis. Elas são identificações em curso, são resultado de processos de identificação e também de auto identificação. Assim, é um processo ativo, em que as goianas buscam ouvir música sertaneja, relembrar o gosto do pequi, fazer atividades que são culturalmente por elas valorizadas, porque estão fortemente envolvidas na manutenção das suas fronteiras e das suas as identidades que assim passam a ser revividas. 


\section{Notas}

${ }^{1}$ Menina: designação dada, em Goiás, ao sexo feminino, enquanto crianças e adolescentes, mas que também se estende até a idade adulta, principalmente quando ainda não se adquiriu o estatuto de mulher casada. Pequi é (Caryocar brasiliense; Caryocaraceae) é uma árvore nativa do cerrado brasileiro, cujo fruto, embora muito utilizado na cozinha nordestina, do centro-oeste e norte de Minas Gerais, é considerado símbolo da cultura do estado brasileiro de Goiás.

${ }^{2}$ Investigador no ICS (Instituto de Ciências Sociais da Universidade de Lisboa).

${ }^{3}$ Para as "histórias de família" ver PINA CABRAL e LIMA (2005:356).

${ }^{4}$ Para preservar a identidade das entrevistadas, todos os nomes que aparecem nas entrevistas são fictícios.

${ }^{5} \mathrm{Http}: / /$ www1.folha.uol.com.br/folha/mundo/ult94u74387.shtml acesso em julho/2009.

${ }^{6}$ Tipo de biquíni feminino. Nota do Editor (n/e)

\section{Referências}

ALMEIDA, Alexandra Gomes e REIS, Ellem Saraiva. A imigração brasileira em Portugal: o perfil do imigrante e as conseqüências no mercado de trabalho luso. $V$ Encontro Nacional sobre Migrações. Campinas, 2007.

BARTH, Fredrik. Introduction. In: BARTH, Fredrik (ed.) Ethnic Groups and Boundaries. The Social Organization of Culture Difference, Prospect. Heights, Illinois: Waveland Press, 1998 (1969).

COSTA, Paulo Manuel. "A legislação de estrangeiros em Portugal: a situação dos cidadãos brasileiros". In: MACHADO, Igor José de Renó. (org.), Um mar de identidades: A imigração brasileira em Portugal, São Paulo: Edufscar, 2006.

COUTINHO, Décio Tavares. Goiás é Bom Demais! - O marketing como potencializador da invenção de uma identidade. Goiânia: Ed. UCG, 2005.

CHIDIAC, Elie. Migrações e Relações Internacionais. Revista UFG. Goiânia, Julho XIII no 10, p. 159-160, 2011.

GIDDENS, Anthony. Sociologia - 6ạ ed. Lisboa: Fundação Calouste Gulbenkian, 2008.

MACHADO, Igor José de Renó (Org.). Um mar de identidades, a imigração brasileira em Portugal. Edufscar, São Carlos, 2006.

MARGOLIS, Maxine L. Na Virada do Milênio: A Emigração Brasileira para os Estados Unidos. In: MARTES, Ana Cristina Braga; FLEISCHER, Soraya (eds). Fronteiras Cruzadas: Etnicidade, Gênero e Redes. São Paulo: Paz e Terra, 2003. 
OLIVEIRA, Sério P. Sem Lenço, Sem documento: Brasileiros Não-documentados em Portugal. In: Machado, Igor José de Reno. Um mar de Identidades: A imigração brasileira em Portugal. São Carlos: EdUFSCar, 2006.

OLIVEM, Rubem G. A. A parte e o todo: a diversidade no Brasil nação. Petrópolis: Vozes, 1992.

PADILLA, Beatriz. Integração dos imigrantes brasileiros recém chegados" na Sociedade Portuguesa : Problemas e Possibilidades. In: Machado, I. J. De R, org. Um Mar de Identidades : Imigração brasileira em Portugal. São Carlos : Edufscar, 2006.

PEREIRA, Juliana . As Meninas do Pequi fora do Sertão: goianas imigrantes em Lisboa. Lisboa: Universidade de Lisboa, Instituto de Ciências Sociais, 2009. Dissertação de Mestrado em Antropologia Social e Cultural.

PINA-CABRAL, João; LIMA, Antónia Pedroso de. Como fazer uma História de Família: um Exercício de Contextualização Social. Etnográfica. Vol. IX (2).2005

RIBEIRO, Gustavo Lins. Goiânia, Califórnia. Vulnerabilidade, ambigüidade e cidadania transnacional. Brasilia. Série Antropologia, n. 235, 1998.

RIBEIRO, Gustavo Lins. O Que Faz O Brasil, Brazil: Jogos Identitários em San Francisco. pp. 4585. In: REIS, Rossana Rocha; SALES, Teresa (Orgs.). Cenas do Brasil Migrante. São Paulo: Boitempo, 1999.

SANTOS, Boaventura de Sousa. As oportunidades lusófonas. Rua Larga, nำ: 48-49, 2005.

SOBRAL, José Manuel. Pierre Bourdieu e o Estudo da Identidade Nacional. In: PINTO, José Madureira; PEREIRA, Virgílio Borges (Orgs.). Pierre Bourdieu: a teoria da Prática e a Construção da Sociologia em Portugal. Porto: Edições Afrontamento, 2007.

SOBRAL, José Manuel. Cidadania, Nacionalidade, Imigração: um breve historial das suas interrelações com referência ao caso português. In: CARVALHAIS, Isabel Estrada (coord.). Cidadania no Pensamento Político Contemporâneo. Cascais: Editorial Principia, 2008. 


\title{
RESUMO
}

Neste artigo descrevo algumas trajetórias que representam percursos migratórios das imigrantes goianas, que moram em Lisboa. Por meio delas é possível pensar sobre algumas articulações e interseccionalidades que são feitas a partir de marcadores sociais como ser mulher e brasileira num contexto migratório e de que modo esses marcadores ainda se articulam com a categoria regional.

Palavras-chave: gênero, regionalidade, mulheres goianas.

\begin{abstract}
In this article I describe some trajectories that represent the migratory routes of immigrants from Goiás who live in Lisbon. Looking at these trajectories allows us to think about articulations and intersectionalities that are linked to certain social markers, such as being a woman and a Brazilian in a migratory context, and how these markers also articulate with the regional category.
\end{abstract}

Key words: gender, regionality, women goianas 